\title{
Suggestion System as an HRM Tool to be Successful in Organisations in New Zealand: Empirical Evidence
}

\author{
Andries J du Plessis \\ Department of Management and Marketing, Unitec New Zealand, Mt Albert Campus, \\ New Zealand
}

\begin{abstract}
This article reviews literature and presents findings and results of qualitative research conducted by structured interviews. Questionnaire was used to identify the employee involvement in giving suggestions. Findings confirm that HRM needs to have some rewarding system in place for usable ideas to be received through the suggestion system. As a result of this study, additional issues such as the use of software to monitor and measure the implementation of suggestions, distribution of suggestions among all those involved, and a few others was identified. According to the research it was identified that HRM and line managers will always remain pivotal in the success of the suggestion system. Managers should use any possible management tool that contributes to their survival and success in the current competitive economies globally. It was also identified that greater employee involvement leads to greater tangible benefits such as cost savings and sales and intangible benefits such as higher levels of morale. Moreover, motivational effects like recognition and rewarding should not be underestimated. Therefore, it is concluded that a suggestion system is a perfect tool for HRM and managers on their road to success.
\end{abstract}

\section{Introduction}

The view of Du Plessis (as cited in Du Plessis, Nel \& San-Diego, 2013) and Du Plessis (2015) is that human resource management (HRM) should be managed until it becomes a more ordinary part of the daily existence. In order to survive in the current competitive economies in New Zealand, human resource (HR) managers should be creative and innovative and use any possible tool that contributes to their survival and success. One of the most undervalued tools available is the suggestion system. To give stature and structure to the success of the system will, however, depend on a number of factors, such as the manager's commitment and involvement, proper policies, procedures and rules, an affective administration and processing process, objective evaluation of ideas and a fair recognition or rewarding system.

It is necessary for HR managers to have a profound re-think of suggestion systems and what to do with the information gathered from employees to increase their profits, retain their workforce and sustain their competitive advantage. In order to survive in the current competitive economies globally, organisations should use any possible management tool that contributes to their survival. Supporting this statement is data from Statistics New Zealand (2012) that reveal that $86.8 \%$ of businesses in New Zealand generally have 5 and less employees in service with only $3.6 \%$ of businesses in New Zealand having 20 or more employees in service. Therefore, entrepreneurs should use any possible tool to assist or help them to grow and to be successful.

There is an increasing sentiment to "act locally but think globally" resulting in community-based businesses becoming more important in encouraging businesses and public policy practitioners to focus on the significance of people working together to facilitate regional development (Du Plessis, 2015; Du Plessis, Frederick, Maritz, 2013; Kapelus, 2002; Lyons, 2002). Talent management is the key challenge for the next decade (Nel et al, 2014). Human resource practitioners need to operate within the business cycle if they wish to become strategic business partners taking suggestions from their employees on board. It is crucial that the 'talent inventory' (skilled employees), is maintained at the right levels, in order to comply with the requirements of hiring and retention issues. This could only happen if 
HRM is aware of what climate in the workforce in other words if HRM knows exactly what their employees' suggestions are.

In this article the respondents' responses are discussed, with the main findings and results of the research confirming that HRM needs to have some rewarding system in place for usable ideas received through the suggestion system. Additional issues such as the use of software to monitor and measure the implementation of suggestions, distributing of suggestions among all those involved, and a few others were also identified as a result of this study. This article covers a literature review and reports on qualitative research with structured interviews. The analysis section includes a flow chart (Figure 1 below) of effective suggestion systems for HRM to follow to ensure that all steps are followed to use suggestion systems as an effective tool for getting innovative ideas from their employees; in the analysis of the results the different responses of the respondents are discussed. The evaluation of submitted ideas by employees, the implementation of ideas, whether large financial rewards contribute to team work, what create synergies and opportunities for new ideas in the organisation, whether non-financial rewards are powerful, and recognition and rewards are discussed in the results and discussion section; recommendations and conclusions form the last section of this article.

\section{Methodology}

A number of critical success factors for suggestion systems were identified from the literature. From these critical factors the ten most important once were identified. A questionnaire was compiled by the University of Pretoria (UP) to establish to what extend these critical factors are complied with in organisations. The same questionnaire was used with permission from UP after minor modifications for an identical survey in New Zealand. Minor modifications involved updating and scrapping of some questions because the questionnaire was too long for use during short interviews in New Zealand. The questionnaire was used and completed during personal interviews which were conducted in four main business areas, namely Auckland, Greater North, Manukau and Waitakere City. Table 1 below is a profile of the distribution of the respondents in the four business areas. A $100 \%$ response rate was achieved.

Table 1: Profile of respondents by business area

\begin{tabular}{|c|c|c|}
\hline Business Area & $\begin{array}{c}\text { Number of } \\
\text { organisations }\end{array}$ & $\begin{array}{c}\text { Percentage of } \\
\text { organisations }\end{array}$ \\
\hline Greater North & 6 & $28.57 \%$ \\
\hline Auckland & 10 & $47.62 \%$ \\
\hline Manukau & 4 & $19.05 \%$ \\
\hline Waitakere City & 1 & $4.76 \%$ \\
\hline Total & 21 & $100.00 \%$ \\
\hline
\end{tabular}

Although the results of Statistics New Zealand (2008) revealed that $86.8 \%$ of businesses in New Zealand generally have 5 and less employees in service with only 3.6\% of businesses in New Zealand having 20 or more employees in service, the amount of employees in the organisations in our research project give a different picture. The number of employees employed by the organisations varies from a minimum of six employees to a maximum of 110 , as reflected in Table 2 below.

Table 2: Profile of respondents by organisation size

\begin{tabular}{|c|c|c|}
\hline $\begin{array}{c}\text { Number of } \\
\text { employees }\end{array}$ & $\begin{array}{c}\text { Number of } \\
\text { organisations }\end{array}$ & $\begin{array}{c}\text { Percentage of } \\
\text { organisations }\end{array}$ \\
\hline $6-29$ & 8 & $38.10 \%$ \\
\hline $30-49$ & 8 & $38.10 \%$ \\
\hline $50-110$ & 5 & $23.80 \%$ \\
\hline Total & 21 & $100.00 \%$ \\
\hline
\end{tabular}

From the 21 organisations $90.48 \%$ are from the private sector while $9.52 \%$ are from the public sector. A total of $89.47 \%$ of the private sector organisations are from industry. 


\section{Theoretical Bases}

\subsection{Incentives, Initiative, Idea Generation and Awards}

Employees' ideas and innovations are so important in any organisation because they are on the shop floor and are experiencing the advantages or disadvantages of what they are doing. The initial view should be the assumption that all suggestions are beneficial until the evaluation proves otherwise. Stone (2013) is of the opinion that employees have ideas regardless of whether or not the environment is conducive but the employee will not submit it if the environment is not seen as supportive.

Therefore, organisations must have incentives, which are proactive, in place for employees to feel that submission of their useable ideas will be rewarded. Incentives provide a very direct message to the employee and it is focused on their behaviour in achieving objectives; in our case idea generation programmes and participation in the suggestion system. A common aim of a suggestion system is to achieve greater employee involvement which eventually leads to greater tangible benefits such as cost savings, and higher sales and intangible benefits like higher levels of morale (Crail, 2006). Usually the employee's response follows from substantial exposure to surveys or involvement to generating ideas in the workplace. One of the most pervasive perceptions likely to be encountered is that many of the past initiatives amounted to nothing. This perception normally arises from the absence of feedback on the outcomes or the non-implementation of ideas and HRM should have feedback on the top their "to-do" list.

Creative behaviour conceptualises suggestions as creative acts while initiative adds one particular facet to the creative process idea. The notion of ownership which generally accrues from participation is a major consideration in the implementation of suggestions or ideas. It is through involving various stakeholder constituencies from the onset of the initiative, creating ideas, the pre-implementation stage, and during the diagnoses of generating ideas that psychological ownership for the suggestion programme is established (Van Tonder, 2006). There are different ways for HRM to use the information gathered from their employees (refer to Figure 1 below in the analysis section) but it is important that the method used must be clear, straight forward, and open to all potential participants for all employees to know what to do to receive the award, according to Wood (2003).

\subsection{The Role of Organisational Culture in Generating Ideas}

Organisational culture also plays an important role in the attitude and behaviour of employees. Du Plessis and Sukumaran (2015) and Du Plessis (2007) refer to culture as an important consideration for recognition. In cultures where status differentials are minimised and more individualistic in nature (for example New Zealand, Australia and the USA) a more egalitarian reward system is used rewarding individuals. This reward system includes rewards for suggestions made through the suggestion system. The implementation thereof is not rewarded. Du Plessis (2016) and Ishaya (2006) explain that employees need to be skilled and well trained in their job, with systems in place so that they can work effectively and efficiently to add value to their organisations.

\subsection{The Role of Technology in Involving all Employees When Distributing Rewards}

Technology normally reminds of science and technical subjects; it means a science of industrial and mechanical arts. Furthermore, technology denotes proven methods or systems and processes for attaining output from input. The use of a suggestion system by HRM and managers, therefore, could be the perfect tool in attaining their goal, in other words to be successful as an organisation. More caution rather than less should be exercised by managers to have their employees on board and totally committed to a suggestion programme. Methods to generate ideas should be clear, straight forward and open to all participants, teams and individuals. Figure 1 below is a flow chart to assist HRM and managers to make sure that all possible methods are used and that all levels of employees are involved. Software should be made available and should be used to manage the process effectively and efficiently. The software could replace the traditional suggestion box and should be able to acknowledge receipt, handle duplicated ideas, link ideas to evaluators and allow everyone to search for existing ideas and build on (Du Plessis, 2016).

\subsection{The Importance of Administration}

The administration of the suggestion system seems to be a major hurdle to overcome. Holland, Sheehan, Donohue and Pyman (2007) are supporting what was explained above that information or data received must be evaluated and if useable must be implemented. Recordkeeping is of the utmost importance and the notion of e-admin has taken over. Almost two decades ago already Love (1998) suggested that the system should start small and grow only if necessary. 
Administrative delays result in the employees getting the impression that the organisation does not view their ideas as worthwhile. An early acknowledgement of receipt of the suggestion is essential. Suggestion boxes, traditional ones and electronic ones (e-suggestion boxes), should be "cleared" on a daily basis. The suggestion system coordinator (e-admin coordinator) should make sure that employees who submit an idea receive a personal response to thank them (Figure 1).

\subsection{The Role of Human Resource Management and Line Managers}

The latest trend of pre-employment briefings by HR / employers is fast becoming the norm according to Du Plessis (as cited in Nel et al 2012). These briefings or discussions take place before the employment contract is signed; thus if no agreement or consensus is reached on certain issues, no employment agreement is signed and no further working relationship is established. Suggestion systems could be one of the agenda points during these pre-employment discussions. Usually new employees attend an induction programme before starting their new roles. In small businesses in New Zealand there is no human resource department and new employees rely on HRM/owner/manager to do the induction (Du Plessis, 2016).

An induction programme should include an explanation and awareness of the suggestion system. Dessler (2005) and $\mathrm{Du}$ Plessis (2016) endorse this and add that such information should be given at the second stage of the three conducting stages of induction. Nel et al (2014) point out those policies, including suggestion programmes, should be the responsibility of the HR department. They also state that policies and programmes must be developed in consultation with representatives from trade unions (if the organisation is unionised) and it must comply with relevant legislation. Most small businesses use HR consultants to do all their HR related functions (Du Plessis, 2007; Du Plessis, 2015; Du Plessis, 2016).

\subsection{The Importance of Feedback on Implementation of Accepted Ideas}

Du Plessis and Paine (2007) report that the power of feedback to employees is often underestimated. There is a correlation between the number of suggestions submitted and the time taken to give feedback to the suggestor. In her study Nel (2008) found that two discouraging elements in the suggestion systems are the length of time taken to evaluate a suggestion and secondly the delay in recognition through sometimes poor communication channels. The longer the time to give feedback and recognition, the fewer the suggestions submitted. The more immediate the feedback and recognition the more powerful it will be (refer to Figure 1 below). It is of the utmost importance to give feedback to all employees when accepted ideas or suggestions were implemented.

The importance of suggestion boxes as a tool for successful HRM and managers is immeasurable, therefore no matter how small the idea or suggestion is, if it contributes to the organisation's profitability, survival, sustainability or maintaining its competitive advantage it should be recorded and implemented. The progress of submitted ideas should be monitored by the software in use and that includes implementation and feedback to all employees. The implementation of ideas should also be part of the supervisor's performance appraisal (Du Plessis, 2016). In Figure 1, below, the importance of proper feedback to all stakeholders is pointed out.

\section{Interpretation of the Investigations}

\subsection{Discussion}

In the empirical study it was found that only $19.05 \%$ of the organisations claimed to have a formal suggestion system, meaning they have an official policy, certain structures and procedures in place. It is interesting to note that none of the organisations, whether formal or informal, have an exclusive name for their system. It could therefore be concluded that managers will refer to "the suggestion system or suggestion scheme". Not one of the respondents believes that the name of the system will contribute to the success on the system. Buchanan and Badham (2008) go one step further in saying that employees must have a conceptual understanding of the system and a name linked to it.

There was consensus among all the participating organisations that the evaluation of suggestions is completed in less than 90 days after it was submitted. This is an indication that the management is open for suggestions and that they value the ideas of employees. The fact, however, that $71.43 \%$ of the respondents either disagree or do not know whether suggestors are getting feedback on a regular basis during the evaluation period places a question mark on the commitment of management. The flow chart (Figure 1) below explains the flow of feedback. 
An alarming $38.10 \%$ of the respondents reported that their employees from all levels are not involved in the design of the idea generation system. A further $28.57 \%$ of the respondents were unsure; therefore, two thirds $(66.67 \%)$ of their organisation's employees are excluded in the basic design of what could be a possible cost saving or a possible labour turnover decrease. Only a third (33.33\%) of the respondents is sure that their employees are involved and contribute positively to possible cost saving or attaining of their competitive advantage.

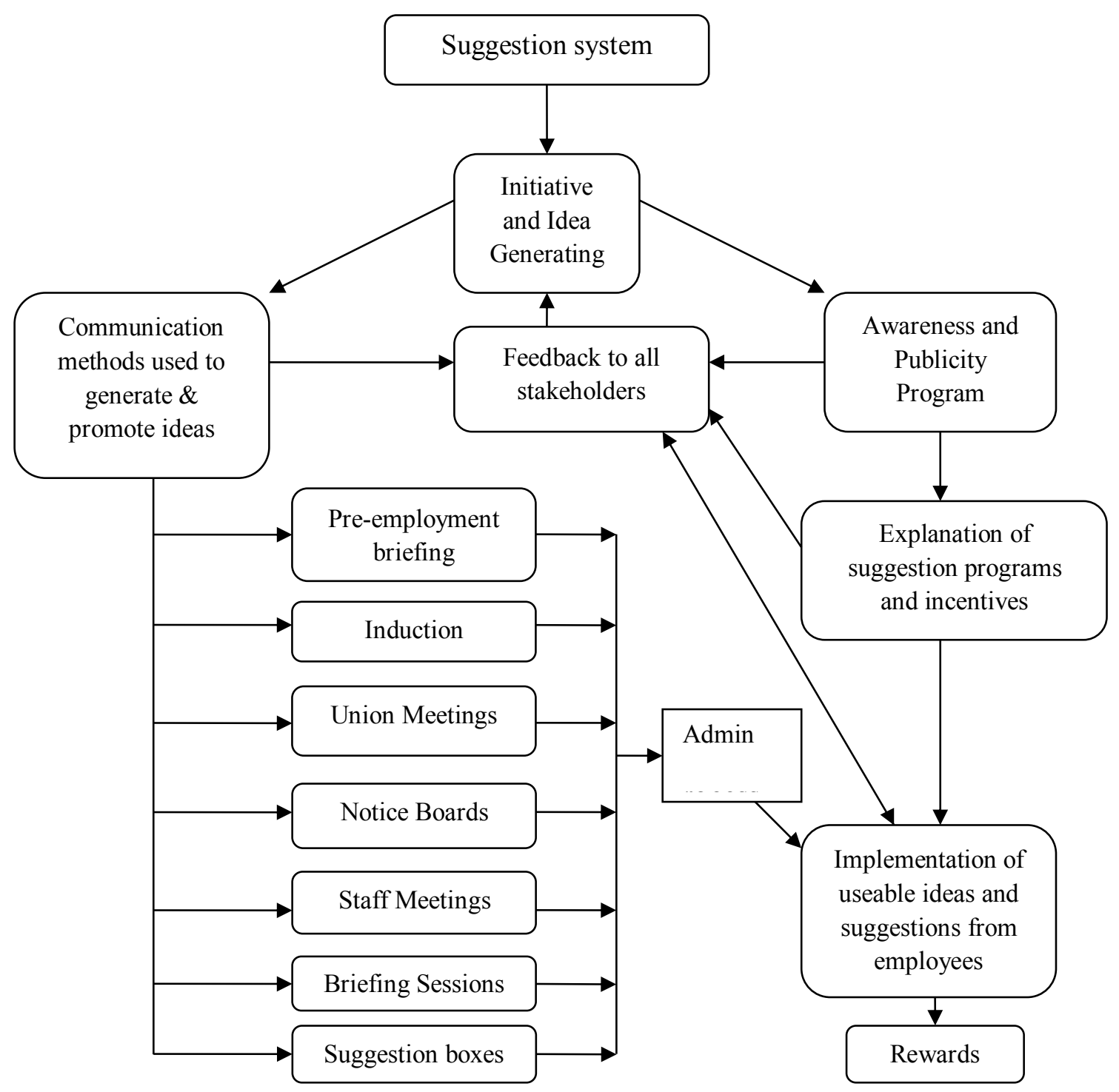

Figure 1: Flow Chart for HRM and managers to use in their Suggestion Systems

Source: Developed by the author

\subsection{Awards}

Managers have to ensure that their employees are aware that there is an award system for accepted suggestions. Only $38.09 \%$ of the respondents agreed that they make it worthwhile for their employees to share their new ideas with the manager. It can be deduced that managers will have to adapt an attitude that they are not the "mister know all" in the world and if they are prepared to reward their employees they might just get more usable ideas.

\subsection{Do Employees Know What to Do to Get the Award?}

Only $4.76 \%$ of the respondents reported that they know exactly what to do to get any award for their suggestions. The fact that $19.05 \%$ of the respondents agree that their suggestion evaluators haven't received proper training for the programme and evaluation techniques, proves a serious lack of commitment from management to ensure that ideas from employees get the necessary attention. An alarming $80.95 \%$ don't know whether suggestion evaluators do receive 
appropriate training in the reasons for suggestion systems and evaluation techniques is further supporting the fact that employees don't know what to do to receive an award. It also shows that management could get substantially more involved, at least in training their employees in "the why" and "the how" of the programme and to receive an award. A total of $57.14 \%$ of the respondents are not exactly sure what to do to get the award for their suggestions.

\subsection{Financial Awards and Feedback}

Almost half of the respondents (42.86\%) disagree that management make any financial awards for their suggestions accepted, whereas $47.52 \%$ is not sure. Holland, Sheehan, Donohue and Pyman (2007) link recognition and awards to the psychological contract. Although it might not be a written clause in their employment agreement, employees do want to be recognised or rewarded for their efforts and achievements in the organisation under the psychological contract, if their suggestions are accepted. A third (33.33\%) of the respondents agrees that large financial rewards do not contribute to teamwork. It is also important to take note of the other respondents because $52.38 \%$ are in favour of large financial rewards. It can be deduced that employees value their contribution to the organisation and want to be rewarded for this extra efforts such as suggestions. In support of this statement only 14.29\% reported that the organisation will get more suggestions without being offered any rewards. Feedback is regarded as very important, but $61.43 \%$ of the respondents don't want this feedback during their performance appraisals.

\subsection{Distribution of Rewards Create Synergies}

A surprisingly positive response was received from the respondents as $57.14 \%$ of the respondents want suggestion rewards to be distributed among all those involved in the process; they are also positive that the implementation of ideas creates synergies and opportunities for more new ideas. Only $4.76 \%$ did not agree with this. A very strong response $(95.24 \%)$ was received that non-financial recognition is just as powerful as financial rewards.

\subsection{The Role of HRM and Line Managers' Responsibilities}

Line managers must accept responsibility and be accountable for what is happening in their work sections for which they are designated according to Clegg, Kornberger and Pitsis (2008). Some of the reasons are that suggestions originating in a specific section are usually referred to the line manager; they decide whether the suggestion will be accepted or implemented, especially when it relates to their particular area of supervision. If they suppress the initiatives of their subordinates, they will be unable to motivate their employees to participate. As pointed out above most New Zealand organisations have about five employees and therefore no HR department. This is the reason why the responsibility is on the shoulders of the line manager and HRM has basically no role to play in the implementation stage, but certainly in the induction stage of new employees in larger firms but not in these small organisations.

With reference to whose responsibility it is to implement ideas, only $14.29 \%$ of the respondents believe it is the suggestor's line manager's responsibility to see to it that accepted suggestions are implemented while $9.52 \%$ disagree and an alarming high percentage, more than three quarters $(76.19 \%)$ are not sure. If the line manager does not take the responsibility and there is no HR department involved, who must? Surely, the suggestor cannot implement the suggestion without the approval of the line manager?

\subsection{Organisational Culture in Generating Ideas}

Organisational culture is the pattern of basic assumptions, values, norms and artefacts (the highest level of cultural awareness) shared by the organisation's members, according to Waddell, Cummings and Worley (2011). Therefore, if the norm or assumption in the organisation is that suggestions are implemented by line managers, everybody will expect and even wait for the line manager to do their job. It can be deduced that if there is agreement on this, then it is the responsibility of the line manager and, according to the respondents, they are not even sure that it is one of their duties as line manager. Line managers are often the most important link in the idea generation programme. Employees and line managers are the people with the most knowledge of the job and it came as a surprise that $66.66 \%$ of the respondents admitted that no explanation of the suggestion programme forms part of the induction programme in their organisations. In Figure 1 above it is clear that the awareness and publicity programme follows the idea generating programme. The explanation could easily be done during the pre-employment or the induction period. 


\subsection{Administration and Technology}

The question was put forward to the respondents whether software is used to submit and process suggestions. Only $4.76 \%$ of the respondents agreed that software is in use for administration and processing. Almost all (95.24\%) of the respondents responded that they don't use any software for the said issues. It can be deduced that the organisations are too small to layout huge amounts of money on systems that they think could be managed manually.

\section{Some Implications for HRM and Managers}

After analysing the data collected it is concluded that HRM and managers should have a much better knowledge of suggestion systems and its value add in their organisations. This would help them understand and interpret also recognition, awards, rewards and the use of non-financial rewards. Although it might not be a written clause in their employment agreement, employees do want to be recognised or rewarded for their efforts and achievements in the organisation under the psychological contract. The manager must ensure that they do not neglect recognising, rewarding and implementation of useable ideas and suggestions.

The manager's involvement in the idea generation programmes is of the utmost importance to use suggestion boxes as a tool for successful business; without them supporting the programmes, it is hardly likely that subordinates will come up with new ideas. If there is an air of negativity, it will pervade down to the subordinates with the result that participation dwindles.

HRM and managers are engaged in evaluating the suggestions therefore they are instrumental in determining the advantages of the idea. They should maintain a good relationship with their subordinates, develop the idea generation programmes and motivate them to submit their suggestions. Feedback to suggestors should be documented and entrepreneurs should also become active in the system to make it a success.

\section{Conclusions}

HRM and line managers will always remain pivotal in the success of the suggestion system. Managers should use any possible management tool that contributes to their survival and success in the current competitive economies globally. The most under-valued management tool available is the suggestion system which consists of a formal procedure that encourages employees to think innovatively and creatively about their work and work environment, and to produce ideas. Achieving greater employee involvement eventually leads to greater tangible benefits such as cost savings, better sales and intangible benefits such as higher levels of morale are some of the goals.

Managers must have incentives in place in their organisations for employees to feel that submission of their useable ideas will be rewarded. Explanation and awareness of the suggestion system could be done during the pre-employment stage or the induction stage. Administrative delays result in the employees getting the impression that the organisation does not view their ideas as worthwhile but it can be minimised with the use of software to manage the process effectively and efficiently. Feedback should also be given to all stakeholders as is explained in Figure 1. A flow chart (Figure 1) was developed to assist HRM and managers in the suggestion system process. Some interesting responses were discussed and some implications for entrepreneurs were pointed out. The motivational effect that recognition and rewarding have, must never be under estimated. Therefore, it is concluded that a suggestion system is the perfect tool for HRM and managers on their road to success.

\section{References}

- Buchanan, D. A. \& Badham, R. J. 2008. Power, Politics and Organisational Change. Sage Publications, London.

- $\quad$ Clegg, S., Kornberger, M., Pitsis, T. 2008. Managing Organisations. Sage, London

- Crail, M. 2006. Fresh ideas from the floor. Personnel Today, June 20, 2006, p. 30.

- Dessler, G. 2005. Human resources management. 7th ed Upper Saddle River, NJ: Prentice-Hall

- $\quad$ Du Plessis, A.J. 2016. The contribution of policies, procedures and rules for successful suggestion systems in organisations: some research findings. Journal of Community Positive Practices 16 (1): 92-106 
- Du Plessis, A.J. 2015. HRM and ER in South Africa: Contemporary theory and practice. In: A.J. Du Plessis (Ed.). Munyeka, W., Chipunza, C., Samuel, M. O.,Naidoo, K., Keyser, E. \& Gura, M. Juta Publishers, Cape Town, South Africa.

- Du Plessis, A. J. \& Sukumaran, S. 2015. The role of HRM in leadership development, talent retention, knowledge management, and employee engagement. World Journal of Social Sciences, 5 (1) January: 93-110

- Du Plessis, A.J. 2007. Change, Organisational Development and Culture: Human Resource's role in a future S A. International Review of Business Research Papers. 3(1), March: 1-10.

- Du Plessis, A. J., Paine, S. 2007. Managing of Human Resources and Employment Relations in New Zealand's Retail Industry. The International Journal of Knowledge, Culture and Change Management. 7(2): 83-91

- Du Plessis, A. J., Frederick, H., Maritz A., 2013. Education and training deficits in industrial clusters: Empirical evidence that managers can use to rectify the skills gap in Auckland precinct. National Academy of Management. Actual Problems of Economics, 2 (3): 12-20

- Holland, P., Sheehan, C., Donohue, R. \& Pyman, A. 2007. Contemporary issues and challenges in HRM. Tilde University Press, Australia.

- Ishaya, S. 2006. Building conscious workplaces and harmonious teams. Human Resource New Zealand Magazine. 10 (6) February: 30-31

- Kapelus, P. 2002, September). Mining, Corporate Social Responsibility and the Community: The Case of Rio Tinto, Richards Bay Minerals and the Mbonambi. Journal of Business Ethics, 39(3), 275-296. Retrieved April 13, 2008, from Business Source Premier database, CrossRef

- $\quad$ Love, T. 1998. Managing your small business. Nation's Business, 86, (5), p. 11.

- Lyons, T. 2002, August. Building Social Capital for Rural Enterprise Development: Three Case Studies in the United States. Journal of Developmental Entrepreneurship, 7(2), 193.

- Nel, L 2008. The usefulness of corporate ethics programmes in integrating ethics into an organisation's culture. Unpublished Master of International Communication Thesis, Unitec New Zealand.

- Nel, P. S., Werner, A., Du Plessis, A. J., Fazey, M., Erwee, R., Pillay, S., Hearn Mackinnon, B., Millett, B., Wordsworth, R. (2012 Human Resource Management in Australia \& New Zealand. Oxford University Press, South Melbourne, Victoria, Australia.

- Nel, P.S, Werner, A, Botha, C.J, Du Plessis, A.J, Mey, M, Ngalo, O, Poisat, P \& Van Hoek L. 2014. Human Resources Management. 9th ed. Cape Town: Oxford University Press.

- Peredo, A., \& Chrisman, J. 2006, April. Toward A Theory of Community-Based Enterprise. Academy of Management Review, 31(2), 309-328, CrossRef

- Statistics New Zealand 2012. "Regional Statistics by Subject Matter” www.stats.govt.nz

- Stone, R. J. 2013. Human resource management. 7th edition. John Wiley \& Sons, Australia Ltd

- Van Tonder, C. L. 2006. Organisational change. Van Schaik Publishers, Pretoria.

- Waddell, D. M., Cummings, G. T. \& Worley, C. G 2011 Organisation development and Change. Thompson, Melbourne, Australia.

- Wood, A. 2003. Managing employees' ideas: From where do ideas come? The Journal for Quality and Participation, 26, (2), p. 22. 